\title{
Correction to: Using online peer assessment in an Instructional Technology and Material Design course through social media
}

\author{
Mehmet Demir ${ }^{1,2}$
}

Published online: 22 February 2020

(C) Springer Nature B.V. 2020

\section{Correction to: Higher Education https://doi.org/10.1007/s10734-017-0146-9}

The original version of this article unfortunately requires correction with respect to the affiliation of the author. The correction is shown below and this is already reflected in the affiliation section of this Correction (Erratum) paper:

Affiliation 1: Department of Curriculum and Instruction, School of Education University of Pittsburgh, Collaborative for Evaluation and Assessment Capacity, 4139 WWPH 230 S. Bouquet St., Pittsburgh, PA 15260, USA

Affiliation 2: Saray Kent mah. Dogukan sk. Mirac apt. Kat 4 No:10 Antakya/Hatay/ Turkey

Publisher's note Springer Nature remains neutral with regard to jurisdictional claims in published maps and institutional affiliations.

The online version of the original article can be found at https://doi.org/10.1007/s10734-017-0146-9

Mehmet Demir

mdemir@pitt.edu; malpdmr@gmail.com

1 Department of Curriculum and Instruction, School of Education University of Pittsburgh, Collaborative for Evaluation and Assessment Capacity, 4139 WWPH 230 S. Bouquet St., Pittsburgh PA 15260, USA

2 Saray Kent Mah. Dogukan Sk. Miraç Apt. Kat:4 No:10, Antakya/Hatay, Turkey 